\title{
Macintyre's After Virtue and the Disagreement about Disagreement
}

\author{
Germán Meléndez*
}

\begin{abstract}
It is the purpose of this paper both to define the problem which MacIntyre is aimed at solving in After Virtue and to locate the basic assumptions and contentions on which the argument for his main proposal, i.e. a revival of Aristotelianism, ultimately rely. This task seems rather unproblematic itself and simply accessible to an attentive reading of the text. However, as I hope to show, a precise characterization of the problem, of the argument and, even, of the main thesis of After Virtue happens to be, at a closer look, evasive (to say the least), given the intricate way in which MacIntyre presents his ideas. The present paper is, in the main, a successive reformulation of each of the aforementioned issues. What initially gives itself as the problem to be solved and what, at first instance, the argument appears to be pointing to, requires in each case substantial qualification as soon as one tries to make out of the text a unified and self-contained whole. The remarkable fact that our sight begins to blur in the same measure as the demand for focus and contour is applied to the text might have been the price to pay for the impressive way in which the author tries to keep track of such comprehensive and multifarious strands of thought as his ambitious task seems intrinsically to require.
\end{abstract}

Keywords: MacIntyre, virtue, disagreement, Aristotle

\section{Tras la Virtud de MacIntyre y el desacuerdo sobre el desacuerdo}

Resumen: El propósito de este trabajo es no solo definir el problema que MacIntyre pretende resolver en "Tras la virtud" sino también localizar las suposiciones básicas y controversias en las que el argumento de su propuesta principal, es decir, el renacimiento del aristotelismo, en últimas, depende. En sí misma parece una tarea sin problemas y simplemente abordable mediante una lectura atenta del texto. Sin embargo, como espero demostrar, una precisa caracterización del problema, el argumento, e incluso la tesis principal de "Tras la virtud", al mirarlos de cerca son

* Universidad Nacional de Colombia. gamelendeza@unal.edu.co 
evasivos (por decir lo menos), dada la forma intrincada en que MacIntyre presenta sus ideas. Este trabajo es, en general, una reformulación sucesiva de cada uno de los problemas mencionados. Lo que inicialmente emerge como el problema a resolver y lo que, en primera instancia, el argumento parece estar indicando, requiere en cada caso una calificación sustancial cuando uno trata de recoger del texto un todo unificado y autónomo. El hecho notable de que nuestra visión comience a difuminarse en la misma medida en que la demanda de atención y el contorno se aplica al texto podría haber sido el precio a pagar por la forma impresionante en el que el autor trata de hacer un seguimiento de estas líneas generales y múltiples del pensamiento según su ambiciosa tarea parece intrínsecamente requerir.

Palabras clave: MacIntyre, la virtud, el desacuerdo, Aristóteles.

\section{Après la Vertu de MacIntyre et le désaccord sur le désaccord}

Résumé: Le but de ce travail n'est pas uniquement de définir le problème que MacIntyre prétend résoudre dans «Après la vertu », mais il s'agit également de localiser les suppositions basiques et les controverses dans lesquelles l'argument de sa proposition initiale, c'est-à-dire, la renaissance de l'aristotélisme, dépend finalement. En soi, cela semblerait un travail simple et abordable à travers une lecture attentive du texte. Cependant, tel que je pense le montrer, une caractérisation précise du problème, l'argument, et même la thèse principale de "Après la vertu », en les regardant de près, sont évasifs (pour dire le moins), vue la manière confuse avec laquelle MacIntyre présente ses idées. Ce travail est, de manière générale, une reformulation successive de chacun des problèmes mentionnés. Ce qui au début apparait comme un problème à résoudre et ce que, en première instance, l'argument semble indiqué, demande pour chaque cas une qualification substantielle lorsque l'on essaie de prendre du texte un tout unifié et autonome. Le fait notable que notre vision commence à s'estomper alors que la demande de concentration et le contour s'applique au texte pourrait avoir été le prix à payer du fait de la manière impressionnante avec laquelle l'auteur essaie de réaliser un suivi de ces lignes générales et multiples de la pensée selon son ambitieux et exigeant travail.

Mots-clés: McIntyre, la vertu, le désaccord, Aristote. 


\section{Introduction}

It is the purpose of this paper both to define the problem which MacIntyre is aimed at solving in After Virtue and to locate the basic assumptions and contentions on which the argument for his main proposal, i.e. a revival of Aristotelianism, ultimately rely. This task seems rather unproblematic itself and simply accessible to an attentive reading of the text. However, as I hope to show, a precise characterization of the problem, of the argument and, even, of the main thesis of After Virtue happens to be, at a closer look, evasive (to say the least), given the intricate way in which MacIntyre presents his ideas. The present paper is, in the main, a successive reformulation of each of the aforementioned issues. What initially gives itself as the problem to be solved and what, at first instance, the argument appears to be pointing to, requires in each case substantial qualification as soon as one tries to make out of the text a unified and self-contained whole. The remarkable fact that our sight begins to blur in the same measure as the demand for focus and contour is applied to the text might have been the price to pay for the impressive way in which the author tries to keep track of such comprehensive and multifarious strands of thought as his ambitious task seems intrinsically to require.

The first section gives an initial synoptic presentation of what MacIntyre takes to be the epicenter of contemporary moral crisis and of the causes which MacIntyre suggests as indicative of a virtual solution to such crisis. It subsequently proceeds to show how MacIntyre's task requires of a two-leveled argumentation which has to appeal on the first level to a normatively informed historical narrative and on the second level to a partly systematical but also partly historical justification of precisely that historical (or narrative) type of rationality deployed on the first level. This first section focuses on the second-order argumentation and drives to the conclusion that MacIntyre's own strictures concerning the structure of a rational argument in favor of a revival of the Aristotelian tradition of moral thought requires an important qualification of the initial too drastic picture of the origin of modern philosophy as the aftermath of a catastrophe. On the other hand, the more basic task of a justification of such strictures turns out to be, as shown in the second section, just a desideratum the fulfillment of which MacIntyre postpones to his later Whose Justice? Which Rationality? What systematically constitutes a preliminary step has been chronologically deferred.

The third section is concerned with what I have referred to as first level of MacIntyre's argument. It tries to show the way in which MacIntyre's critique of modern morality is articulated. This critique has both a normative and a descriptive component. What the former is concerned, MacIntyre expects the reader to agree without further argument about the existence of contemporary moral disagreement and suggests a connection of this phenomenon with other recognizable features of our present. What the latter is concerned, he expects that the reader agrees in the negative and critical character of radical moral disagreement and those other related features of our contemporary world. Taken that much for granted, MacIntyre argues, again on the descriptive level and as part of his causal analysis for an intrinsic connection between such outstanding negative symptoms of the present crisis and what can be taken as the central invention of modern moral philosophy: the autonomous self. It follows from this connection that MacIntyre gives an inverted valuation of the modern ascent of 
the autonomous self when compared with the current (viz. liberal) assessment of this process as acknowledgedly definitory for the Enlightenment. The crucial step in After Virtue is the explanation of the correlated emergence of both the insoluble moral disagreement and the modern self as the result of a lack: the lack of a teleological framework as the necessary condition for a rational discourse on the virtues. On a conceptual level this lack deprives the key concepts operating in the premises of moral discourse of their functional character and on the sociological level deprives the individual of any social identity. Autonomy actually amount to anomie.

In the final section, it is suggested, that a comparison between MacIntyre's characterization of the fifth and fourth century B.C. Athenian crisis and of our contemporary crisis leads again to an important qualification of what initially seems to be the point of the argument in After Virtue. For, it turns out that the phenomenon of radical moral disagreement is not exclusive of the modern world and that, obviously enough, the causes of such disagreement cannot be found neither in the anachronism of a modern autonomous ego nor in the disruption of a not yet existent Aristotelian tradition. It has then to be called to attention that MacIntyre's objection against the modern world is not actually the existence of moral disagreement but, more precisely, the existence of insoluble moral disagreement. MacIntyre underlines the fact that Greek ethical thought, even amidst severe disagreement on the nature of virtue in general and of singular virtues in particular, continued to define them within the teleological context provided by the polis and the agon. This teleological framework of the virtues, theoretically grasped by Aristotle in his ethical theory, preserved, so it seems (on this point is MacIntyre's account far from clear), the possibility of restoring some agreement on a new level. However, these two teleological reference points were themselves, in their disparity, the responsible source for the Athenian fifth century radical moral disagreement.(On this point, After Virtue casts a shadow which only later Whose Justice, Which Rationality will dissipate). This calls for a further qualification of MacIntyre's contention in After Virtue. The presence (or in our case: the restoration) of a teleological framework, even through a reformulation of the driving ends and goods, does not exclude the unavoidable possibility of radical moral disagreement. It does allow however, at the same time, for the restoration and temporal consolidation of agreement without which no productive redefinition of the ends on which every healthy, i.e. evolving, tradition is ultimately dependent, would be possible. Paradoxically, MacIntyre turns out to be an apologist of 'real' progress in the sense of progress within traditions productively renewed by conflict. If this is an adequate interpretation, MacIntyre's critique of the Enlightenment could be rephrased as a critique of the Enlightenment's moral disagreement as sign of stagnation and dispersion. The Enlightenment would be just the frenetic illusion of constant progress. Or, if one may allow liberalism raise here at least and at last a question, can real progress take place despite, or precisely because, of this lack of agreement on goods and ends? Disagreement on the meaning of 'progress' has been since ever the constant disagreement since modernity gave birth to its critics. In this respect, in fact, nothing has changed. At least in this respect, one would have to give MacIntyre some reason.

\section{Rational Justification and the Justification of Rationality}

MacIntyre belongs to a tradition of thinkers who claim that our contemporary world faces a deep crisis and, more particularly, he belongs to those who are concerned in showing that this crisis is mainly a moral crisis. MacIntyre locates the main feature of this crisis in the fact that "there seems to be no rational way of securing moral agreement in our culture (MacIntyre 1984: 6)." This structural incapability of modern moral discourse to settle interminable moral disagreement is directly linked with the fact that the ultimate premises on which the conflicting moral arguments are 
based are incommensurable, i.e. irreconcilable. They involve, according to MacIntyre, concepts of the most heterogeneous historical origins which have survived the disruption of the original contexts in which they were imbedded and from which they originally acquired their argumentative function and the possibility of their rational justification. Once these concepts have become isolated fragments after the dissolution of the conceptual scheme to which they organically belonged they might well carry an afterlife but, so to say, no longer a rational one. They are no longer capable to give account of themselves, viz. of the ultimate grounds of their normative value. Following one of the most powerful illustrations of this thesis on modern moral disagreement, MacIntyre compares the irrational afterlife of our basic moral concepts to that of the concept 'taboo' in Polynesian culture.

Deprive the taboo rules of their original context and they at once are apt to appear as a set of arbitrary prohibitions, as indeed they characteristically do appear when the initial context is lost, when those background beliefs in the light of which the taboo rules had originally been understood have not only been abandoned but forgotten.

In such a situation the rules have been deprived of any status that can secure their authority and, if they do not acquire some new status quickly, both their interpretation and their justification become debatable. (Ibidem: 112).

The key concepts of modern moral thought faced a similar fate. MacIntyre traces the catastrophic disruption of their original context back to the origin and the foundations of the modern world, viz. the Enlightenment. MacIntyre's assessment of this crucial historical moment couldn't be more clear and emphatic: "one must hold that the Enlightenment project was not only mistaken, but should never have been commenced in the first place (ibidem: 118)." The history of the Enlightenment is the history of a mistake and its catastrophic consequences and the sources of this terrible mistake, despite its undeniable sociological connotations, are to be found first of all, according to MacIntyre, in the realm of moral philosophy ${ }^{1}$, more particularly, within the ethical principles of modern liberal individualism (cf. ibidem: 2).

Now, the question of whether our culture stands in a deep crisis or not, the question whether, if it does, its nature necessarily has to be described in terms of interminable moral disagreement, and the question whether, if this is the case, its causes are to be found in the heritage of the Enlightenment, are all certainly themselves a matter of deep disagreement. One does not need to go too far to find evidence for this fact. It is the rule in the ongoing discussion about the so-called postmodernity, or, in other words, in the debate concerning the alleged obsolescence or the alleged persisting historical relevance of the foundations of the Enlightenment project. Despite all its lack of a precise contour (due, at least partially, to the comprehensive character of the issues involved) and despite all its lack of conclusive power (which MacIntyre could surely interpret as highly symptomatic of the crisis itself) this discussion is undoubtedly an important part not only of contemporary philosophical debate but, insofar as it pertains the stance of our culture in general, is also part of the present discussion in the apparently so heterogeneous realms of art, sociology, politics, natural science. Now, with such a 'disquieting suggestion' as we have just taken over from the introductory chapter of his book, MacIntyre has just taken sides in this interminable controversy which has so far shown to be also resistant to any kind of substantial agreement.

As a matter of fact, MacIntyre is willing to take the disagreement about the existence or the character of the crisis into account as an important part of what the thesis proposed by him in After Virtue has to explain (cf. ibidem: 4), namely, 'interminable' moral disagreement in general. For, according to MacIntyre, our divergent perception, viz. evaluation of the present condition of 'our culture' is itself rooted in,

1 "What I am going to suggest is that the key episodes in the social history which transformed, fragmented, and, if my extreme view is correct, largely displaced morality [...] were episodes in the history of philosophy, that it is only in the light of that history that we can understand how the idiosyncrasies of everyday contemporary moral discourse came about [...]." (Ibidem: 36 ). 
and is an expression of, the moral disagreement which constitutes the main symptom of the actual crisis. MacIntyre is here raising, on the one hand, the uncontroversial and trivial claim that the perception of a certain situation or development in terms of crisis, failure, disorder, necessarily involves certain evaluative standards ( $c f$. ibidem: 3) and that these standards are themselves ultimately moral ones. But MacIntyre is not just pointing to the mere existence of a certain dysfunction nor is he just stressing the need for an etiological definition of the crisis. He is making the claim that such an etiology must necessarily be a historical one. He is making the controversial claim that a purely analytical approach to the critical phenomenon (i.e. moral disagreement) under investigation must necessarily fail "to reveal the fact of this disorder" (ibidem: 2, cf. ibidem: 112s.) and so would also fail a value-neutral historical approach ( $c f$. ibidem: 4). Now, according to MacIntyre, both the unhistorical analytical and the historical but value-neutral approach to ethics are to be conceived as representative of a certain position only intelligible as part of the history of modern moral philosophy, more particularly, as part of the tradition of liberal individualism. MacIntyre undertakes the task of explaining on the basis of a normative historical account, the origin of both the ahistorical approach to ethics (which mistakenly assumes an opposition between reason and historicity, e.g. tradition, (cf.ibidem 222) and the fact-value (is-ought) distinction ( $c f$. ibidem: 56ss.) as a particular extension of the all-pervasive moral disagreement.

As it stands, MacIntyre is thus compelled by the nature of his own historical approach to ethics to present the opposing philosophical views as an essential part of the explananda of his theory ${ }^{2}$. Since one of the essential features of MacIntyre's ethical theory lies ostensibly in his attempt to take his standpoint within con-

2 "It may seem to many readers that as I have elaborated my initial hypothesis I have step by step deprived myself of very nearly all possible argumentative allies. But is not just this required by the hypothesis itself? For if the hypothesis is true, it will necessarily appear implausible, since one way of stating part of the hypothesis is precisely to assert that we are in a condition which almost nobody recognizes and which perhaps nobody at all can fully recognize. If my hypothesis appeared initially plausible, it would certainly be false." (Ibidem: 4). temporary ethical debate by way of a thorough reflection on the origin of disagreement itself, it is no surprise that he readily takes the theoretical burden of explaining why his opponents in this debate are liable to disagree with him on this issue ${ }^{3}$.

But, naturally enough, given the overall purpose of his work, MacIntyre expects not just to afford an explanation of why a whole array of philosophically significant positions ${ }^{4}$ have appeared on the stage of the modern moral debate but, at the same time, to develop an argument against them. This argument must be necessarily a rational argument at least if we are to believe, that his argumentative praxis in After Virtue already exemplary enacts in some way the solution to the contemporary crisis, namely the capability for a rational settlement of moral disagreement on this decisive meta-level ${ }^{5}$.

3 MacIntyre's argumentative proceedure in After Virtue rests thus in a kind of psychoanalytical faith on the possibility of achieving a theurapeuticeffect on our present by way of waking it to a certain awareness of its moral history, though while recognising that there is an imbedded resistance against perceiving the essential facts of such history as reconstructed by the analyst, viz. the historian of philosophy. (This gives a crucial difference to analytical therapeutics in that in this case the 'patient' may not even be aware that he is ill at all). Recognising this history as one's own, and more important, recognising the evaluative accent that the analyst gives to it in terms of order and disorder, achievement and failure, seems already to presuppose a substantial change in the way in which one defines one's (ethical) identity at least to the extent in which this identity is reflected in the resistance to accept those standards by which such history is informed. If there were no such resistance there would be at least such basic shared moral standards as to finally guarantee agreement on the existence and the genetically accountable nature of contemporary crisis. These standards, being themselves moral, could be interpreted precisely as being the ones capable of securing moral agreement in the present circumstances. And MacIntyre assumes this to be so for he is aware of the fact that the absence of resistance to his appreciation of modern culture would have invalidated his thesis in its very inception.

4 Curiously enough Macintyre does not include the tradition of thought to which he himself might belong as part of the history of modern ethical thought which he writes in After Virtue. He does indeed establish a connection between his philosophy and Aristotle's, but he does not refer to any modern tradition that, like he himself, recurres to a certain, however qualified, revival of pre-modern thought. Does MacIntyre believe that he as a thinker does not belong to any modern tradition (e.g. neo-Aristotelism)? Is he as a modern thinker in a condition similar to the one he depicts as belonging to the modern self?

5 According to MacIntyre disagreement on the level of conflicting philosophical approaches to morality can be itself viewed as a particular extension of universal moral disagreement. This anticipates an objection, which could be prompted at this place, that I am confusing in the name of MacIntyre two different levels of disagreement: disagreement concerning moral issues and disagreement between philosophical theories of moral. For MacIntyre there is no place for such sharp distinction. "Moral philosophies are, before they are anything else, the explicit articulations of the claims of particular moralities to rational allegiance. And this is why the history of morality and the history of moral philosophy are a single history. It follows than that when rival moralities make competing and incompatible claims, there is always an issue at the level of moral philosophy concerning the ability of either to make good a claim to rational superiority over the other (ibidem: 268)." 
The question that naturally arises at this point is whether MacIntyre is reducing his intended criticism of the different currents of modern moral philosophy which he addresses in After Virtue (e.g. emotivism, intuitionism, utilitarianism, analytical philosophy etc.) to a matter of the adequate way of tracing its history, i.e. genealogy. If he knowingly happens to sustain, as he does, that this is in the main the character of his critique, and if he therefore rejects the validity of the objection that he would be thereby incurring in the naturalistic fallacy of pretending to derive values from (historical) facts, he would be unmistakably appealing to standards of rationality radically different from the ones which he thinks to be representative of the liberal standpoint. This is in fact, as we will see immediately, what MacIntyre's own assertions lead us to conclude. Hence, MacIntyre has still to report a further basic disagreement, this time on the issue of the nature of what is to count rational argumentation. If his arguments are to convince his opponents, mustn't he first move them to recognize his standards of rationality?

If the parallelism which MacIntyre sees between morality and moral philosophy can be said to hold also between practical thinking and the theory of practical thinking, or in other words, if this philosophical disagreement on the nature of rationality represents not a purely descriptive failure in the attempt to capture one single given reality but it happens to reflect the actual existence of a multiplicity of standards of rationality on the level of contemporary moral discourse, and if philosophers themselves accordingly make use of different models of rationality, then the problem of moral disagreement digs much deeper than one might initially have believed. The irreconcilability of conflicting moral positions would not simply emerge from the fact that we operate with incommensurable ultimate premises involving concepts of divergent historical origins (cf. ibidem: 10), but also from the fact that we put into action in our arguments different concepts of rationality.

MacIntyre must solve a two-fold task in order to pave the way out of contemporary moral crisis. Firstly, he has to criticize those theories of morality which, in his view, just express and reinforce radical moral disagreement and impede a restoration of our moral language. This critique contains a positive and constructive aspect. MacIntyre has to show how our moral language can be integrated or reinterpreted into an organic whole and for this purpose he will have to argue for the superiority of an Aristotelian type of moral system as the restoring power. However, and this is his other task, in order to show the superiority of this type of theory by means of an historical account he must argue for a certain concept of rationality which can legitimate his way of appealing to history as a rational argument.

MacIntyre does include in his book some basic material for a definition of practical rationality as essentially linked to historical explanation and accountability ${ }^{6}$ and he conveys that it is precisely this type of rationality which must be put also into practice on the level of his philosophical argumentation. MacIntyre claims that an action cannot be rendered intelligible nor can it be accountable if it is not integrated in some kind of historical narrative (cf. ibidem: 209). This essential principle of MacIntyre's theory of action applies also to speech acts in general (and one may conclude that it is also true of philosophical utterances) whose most familiar type of narrative structure is that of the conversation (cf. ibidem: 210$)^{7}$. Now, so as a particular action can only be rendered intelligible and can only be fully accounted for within a narrative context, so human life as a whole can only acquire meaning and be justified (in first place for the subject itself) if it can be rendered in the form of an intelligible story. Without going into further details, we may here just summarily recall MacIntyre's central thesis on this issue, according to which "man is in his actions and practice, as

6 On this particular, MacIntyre's position resembles Hampshire's claim that justification on the level of morality is indissolubly linked to historical explanation (Hampshire, p.6s.). Accordingly MacIntyre, as also Hampshire, are compelled to put the distinction between facts and values into question.

7 The conversation, which seems to be just a particular of the kind of narrative context which MacIntyre is ascribing to human action in general, can be taken in such a way as paradigmatic as to illuminate the whole realm of action: "For conversation, understood widely enough, is the form of human transactions in general. Conversational behavior is not a special sort or aspect of human behavior [...] (ibidem: 211)." 
well as in his fictions, essentially a story-telling animal(ibidem: 216) ${ }^{8}$." This I take to be the ultimate support given by MacIntyre in After Virtue for his conception of rationality. This thesis, it may be remarked, is itself not a historical but a systematic one if any, this is the ground on which MacIntyre invites to a strictly philosophical confrontation. Only if agreement is reached in this particular could he expect any receptivity for his conception of rationality from the side of his opponents.

However, MacIntyre has not explicitly used in these considerations the concept of rationality (he just talks in terms of intelligibility, meaningfulness and accountability). MacIntyre is more explicit in this respect when he proceeds to include the life of the individual and its respective narrative within the life and history of institutions and, more broadly, within the course of a tradition (cf. ibidem: 221ss.). In a short passage, MacIntyre reacts against the usually alleged opposition between reason and tradition ${ }^{9}$ and states:

For all reasoning takes place within the context of some traditional mode of thought, transcending through criticism and invention the limitations of what hitherto been reasoned in that tradition; this is as true of modern physics as of medieval logic. Moreover when a tradition is in good order it is always partially constituted by an argument about the goods the pursuit

8 Although MacIntyre does not offer a conclusive defense nor a systematical description of the notion of rationality involved in the arguments presented by After Virtue, one finds nevertheless important indications. A first glimpse into the necessary constituents of an effective rational argumentation in this regard is schematically offered in Chapter 5 (cf. ibidem: 52ss.). This scheme is then more fully articulated in its paradigmatic Aristotelian version in the chapter on "Aristotle's Account of the Virtues" (Chapter 12). MacIntyre finds, however, that Aristotle's account of practical reason needs some important revision and complementation if it is going to perform in the contemporary world what it allegedly performed in the classical and mediaeval world. In Chapter 15, MacIntyre introduces his own updated understanding of the accountability of action as linked to the necessarily narrative (historical) intelligibility of action. But MacIntyre believes that this gradual approach to an updated concept of practical rationality capable of settling moral disagreement under contemporary circumstances is still insufficient ( $c f$. ibidem: 260). Moreover, as we shall immediately see, he does not believe either that he has yet given an argument of the sort required in order to prove the superiority of an Aristotelian moral theory.

9 Already in chapter 4 ("The Predecessor Culture and the Enlightenment Project of Justifying Morality"), while presenting his interpretation of Kierkegaard, MacIntyre refers to the modern parallel contraposition of reason and authority. He suggests that "the notion of authority and the notion of reason" are, on the contrary, "intimately connected (ibidem: 42)." of which gives to that tradition its particular point and purpose.

So when an institution [...] is the bearer of a tradition of practice or practices, its common life will be partly, but in a centrally important way, constituted by a continuous argument [...]. Traditions when vital, embody continuities of conflict. (Ibidem: 222). ${ }^{10}$

The extent of the crisis viz. catastrophe that MacIntyre is intended to overcome is so pervasive that his task seems each time more difficult and more ambitious. It seems that in order to argue for his concept of rationality, he has also to argue for the acceptance of a certain tradition and the standards implicit in its telos. A circle becomes gradually more evident. The acceptability of his concept of rationality presupposes the acceptance of certain standards which belong to a tradition which is no longer alive or, at least, a tradition from which modern liberalism has radically detached itself long ago ex hypothesi. It is clear that, according to Macintyre, a certain tradition has its own standards of rationality and of what excels in view of its purported ends. Radical differences in moral standards and in standards of rationality are ultimately differences pertaining the attachment to a given tradition. But how can one argue in favor of one tradition and against other? Moreover, how can one argue in favor of a tradition that, as the thesis goes, has been dissolved? Stand history in such a way to our disposition as to allow for such revival?

As a matter of fact, MacIntyre substantially qualifies his initial disquieting suggestion of a catastrophic disruption of the premodern world. After all, he tells us in his account of the heroic and the classical society, the pre modern tradition is not completely destroyed. It can

10 We will later return to the important notion of conflict in its relation to tradition. For the time being it has still to be determined how far does After Virtue go in the fundamental task of defending the concept of a historically argumentative rationality that would allow to proceed to the further task of leading his liberal opponents to an agreement regarding the thesis that the possibility of rational moral agreement can only be restored by an appeal to the superiority of an Aristotelian tradition. It will turn out that Macintyre's argument for an historical conception of rationality has, besides the already highlighted systematic strand, also a historical aspect which he develops in Whose Justice? Which Rationality? 
even provide some firm basis for his argument. This is the sense of attempt to show, on the one hand, that Aristotle "provides a central point of focus" of a whole tradition (ibidem: 119) which is originally rooted in heroic epic societies and dramatically developed in the classical world, while showing, on the other hand, that "even heroic society is still inescapably a part of us all" and that narrating its history is "narrating a history that is peculiarly our own history" (ibidem: 130)? The course of history turns out to be not so discontinuous as MacIntyre's rhetorical image of the 'catastrophe' at the beginning of the modern world suggests ${ }^{11}$.

\section{After Virtue: MacIntyre's Postponed Task}

But we no longer need to agonize in the search for the ultimate argumentative basis of MacIntyre's After Virtue. One of the most striking features of his book lies in the final acknowledgment that it is absent. MacIntyre directly deals with these issues near the end of After Virtue. MacIntyre makes here a clear statement of the conclusions he has been driving to.

My own conclusion is very clear. It is that on the one hand we still, in spite of the efforts of three centuries of moral philosophy and one of sociology, lack any coherent rationally defensible statement of a liberal individualist point of view; and that, on the other hand, the Aristotelian tradition can be restated in a way that restores intelligibly and rationally to our moral and social attitudes and commitments. (Ibidem: 259).

11 Now, since MacIntyre sustains that the premodern world is somehow still a real part of our ethical life, i.e. since he suggests that we still appeal to a premodern way of structuring ethical action (for in what other relevant sense would be then the premodern tradition alive?), despite the image of morality given by modern moral philosophy, then he has at the same time to argue that the latter's basic concepts are conceptual fictions (cf. ibidem: 64) which have been incapable to achieve a real replacement of the preexistent structures of ethical agency. The reasons presented by modern moral philosophy as the foundation of moral action are, in fact no reasons at all, i.e. a masquerade (cf. ibidem: 9), so that there are either no reasons at all or the reasons lie unknowingly elsewhere. Emotivism is the doctrine which, rightly aware of the fallacious character of such reasons as given by modern moral philosophy, illegitimately takes sides for the first part of this disjunction, i.e. it concludes that the modern incapability for giving a rational justification of moral action is not simply a historical episode but corresponds to the very nature of morality as such. Impersonal, rational justification is just the disguise for unarguable preferences and choices.
MacIntyre immediately foresees an objection to his conclusion which, despite its centrality, he, astonishingly enough, has to yield to. However, this objection points to an omission which renders his task as yet unaccomplished rather than to a positive failure which renders his enterprise as misconceived. MacIntyre explicitly describes this omission as merely provisory.

[...] when an issue is settled, it is often because the contending parties -or someone from among them- have stood back from their dispute and asked in a systematic way what the appropriate rational procedures are for settling this particular kind of dispute. It is my own view that the time has come once more when it is imperative to perform this task for moral philosophy; but I do not pretend to have embarked upon it on this present book. My negative and positive evaluations of particular arguments do indeed presuppose a systematic, although here unstated, account of rationality.

It is this account -to be given in a subsequent book- which I shall hope to deploy, and will almost certainly need to deploy, against those whose criticism of my central thesis rests chiefly or wholly upon a different and incompatible evaluation of the arguments. A motley part of defenders of liberal individualism [...] are likely to offer objections of this kind. (Ibidem: 260).

And they have certainly done as the criticism that MacIntyre has to encounter in the Postscript to the Second Edition happens to reveal. (But more of this later). MacIntyre recognizes the limits of his enterprise in After Virtue and refers us to his next book (Whose Justice? Which Rationality? ${ }^{12}$ ) if we want to go beyond them. As yet, let's stress it once again, his argument can only be convincing for those who share a similar concept of what a rational argument is but it is precisely his main contenders who not only would eventually reject the content of these or those of his evaluative premises and standards as unacceptable, but will straightway even ob-

\footnotetext{
2 In the introduction to this work Macintyre addresses the problem in the following words: "Fundamental disagreements about the character of rationality are bound to be particularly difficult to resolve. For already in initially proceeding in one way rather than another to approach the disputed questions, those who proceed will have to assume that these particulars procedures are the ones which it is rational to follow (MacIntyre 1988: 4)."
} 
ject against his standards of rationally. A reason of a Kantian or analytic type will be deaf to MacIntyre's genetic arguments and it is this type of reason which prevails in the liberal side of the fence. We seem to be faced with an historical argument whose validity still depends on some unfulfilled conditions.

Now, even if it is now clear that we are not to expect in After Virtue a 'systematic account' of the type of rationality employed in the defense of the moral theory proposed in it, we may still inquire further about the nature of this yet unargued type of rationality, or what comes to be the same, about the character of the arguments used in After Virtue. Is MacIntyre, as I have as yet just assumed, expecting his genealogy to play the role of critique and if so under what conditions? Is MacIntyre assuming that, if his particular type of historical explanation is a convincing one, the positions thereby explained will be then refuted ${ }^{13}$ ?

The first type of criticism that MacIntyre has to meet in the first section of his Postscript to the Second Edition("The Relationship of Philosophy to History") refer exactly to this issue. MacIntyre's reply shows more clearly than the first edition of his book what we were actually to expect of After Virtue. While acknowledging his use of systematical i.e. analytical arguments in After Virtue (cf. ibidem: 269), he does also stress the limited role they play in practical philosophy in general and in his book in particular.

Analytic philosophy [...] can very occasionally produce practically conclusive results of negative kind. It can show in few cases that just too much incoherence and inconsistency is involved in some position for any reasonable person to continue to hold it. But it can never establish the rational acceptability of any particular position in cases where each of the alternative ri-

13 If this were the case, the refutation will come from what history reveals, but what it reveals, MacIntyre would be liable to the charge of incurring into the naturalistic fallacy of expecting to derive values from fact. Macintyre, however, explicitly rejects the dichotomy facts-values and also, accordingly, the "no ought from is" principle. MacIntyre's history of moral philosophy is acknowledgedly informed by standards (MacIntyre 1984:3). What standards are these? Is he in ultimate instance appealing to such standards on which there is still some agreement despite the pervasiveness of the crisis? And if not, how does its acceptance by the liberal reader come about? val positions available has sufficient range and scope and the adherents of each are willing to pay the price necessary to secure coherence and consistency. (Ibidem: 267).

MacIntyre explicitly rejects the idea that such arguments are sufficient "to establish what is true or false and what is reasonable to believe in moral philosophy (ibidem: 269)," while he, on the other hand, sustains the relevance of an historical approach by holding

not only that historical inquiry is required in order to establish what a particular point of view is, but also that it is in its historical encounter that any given point of view establishes or fails to establish its rational superiority relative to its particular rivals in some specific contexts. (Ibidem: 269).

The type of historicism defended by MacIntyre prevents us from appealing to an ahistorical and timeless reason allegedly invested with "universal and necessary principles" and allegedly capable of evaluating any theoretical or practical proposals independently from the particular historical context and to the particular tradition of inquiry from which they obtain their general aims and their general standards. Only when imbedded in this context can a theory be adequately understood and its rational superiority subsequently be evaluated. One may ask at this point, even if it seems quite otiose, whether this evaluation of the 'rational superiority' of a theory is itself rational and if it is in the same sense in which the theory will appear as rationally superior. After denying the rationality of this evaluation either in a Kantian or an analytical sense of rationality MacIntyre suggests that this kind of evaluation of moral theories is not different from the evaluation of scientific theories. According to this parallelism:

if some particular moral scheme has successfully transcended the limitations of its predecessors and in so doing provided the best means available for understanding those predecessors to date and has then confronted successive challenges from a number of rival points of view while avoiding their weaknesses and limita- 
tions and has provided the best explanation so far of those weaknesses and limitations, then we have the best possible reason to have confidence that future challenges will also be met successfully, that the principles which define the core of a moral scheme are enduring principles. And just this is the achievement that I ascribe to Aristotle's fundamental scheme in After Virtue. (Ibidem: 270).

This is the positive and constructive task of After Virtue (chapters 10ss.) that follows his direct critique of modern moral philosophy (chapters 2-9). MacIntyre's critique is two-sided. On the one hand, there is an immanent (ahistorical) critique which results from applying to modern moral philosophy the test of consistency but can only serve a limited refutative purpose ${ }^{14}$. On the other hand, there is a critique which provides

the grounds for understanding those failures [the failures of the protagonists of the Enlightenment] [...] out of the resources afforded by an Aristotelian account of the virtues, which in just the way that I have described, turns out to emerge from its specific historic encounters as the best theory so far. (Ibidem: 271).

We may here overlook the first kind of critique since it presumably makes exclusive use of the purely negative, i.e. refutative, power of non-historical analytic argumentation. We turn to the second kind of critique, the one which MacIntyre might claim as specific of his own philosophy, the one which should exhibit the rational superiority of an Aristotelian moral theory and should represent the decisive move of After Virtue towards securing the possibility of a rationally settlement of contemporary moral disagreement. But MacIntyre himself warns us again in his Postscript, as he had already done in the last pages of After Virtue, from looking back to it with the hope of finding the full argument for the contention that the Aristotelian theory is "the best theory

14 MacIntyre concedes that he makes use of this kind of arguments: "when Frankena correctly says that on occasion I employ arguments drawn from analytical philosophy to establish that a particular theory or set of theories fails, he imputes to me nothing that is inconsistent either with my historicism or with my rejection of the view that analytic philosophy can never provide sufficient grounds for the assertion of any positive standpoint in moral philosophy ibidem: 269)." so far": "But note that I did not assert in After Virtue that I had as yet sustained that claim, nor do I claim that now (ibidem: 271)."What was then the book to accomplish? We have jumped from the introductory chapter to the last pages and the Postscript to After Virtue and we know that we do not need to go back in order to look for the complete solution of the problem presented. But perhaps we can find whether and how After Virtue accomplishes the task of paving the way for a solution. The question to ask, within the limits of After Virtue, is then to what extent MacIntyre's argument would be valid if one simply anticipates and takes for granted the positive outcome of MacIntyre's enterprise of justifying his own concept of rationality ${ }^{15}$. Is MacIntyre's argument satisfactory according to his own standards of a story-telling rationality? Are MacIntyre's stories cogent as stories? ${ }^{16}$

15 Although MacIntyre does not offer a conclusive defense nor a systematical description of the notion of rationality involved in the arguments presented by After Virtue, one finds nevertheless important indications. A first glimpse into the necessary constituents of an effective rational argumentation in this regard is schematically offered in Chapter 5 (cf. ibidem: 52ss.). This scheme is then more fully articulated in its paradigmatic Aristotelian version in the chapter on "Aristotle's Account of the Virtues" (Chapter 12). MacIntyre finds, however, that Aristotle's account of practical reason needs some important revision and complementation if it is going to perform in the contemporary world what it allegedly performed in the classical and mediaeval world. In Chapter 15, MacIntyre introduces his own updated understanding of the accountability of action as linked to the necessarily narrative (historical) intelligibility of action. But MacIntyre believes that this gradual approach to an updated concept of practical rationality capable of settling moral disagreement under contemporary circumstances is still insufficient (cf. ibidem: .260).

16 Disagreement at this level can take two different forms. On the one hand, as already suggested, since MacIntyre's historical accounts are themselves informed by some moral standards (cf. ibidem: 3 ), disagreement may arise from disagreement on the moral standards involved in his historical accounts. One might be tempted to distinguish this kind of disagreement from disagreement concerning the descriptive content of such historical accounts. But MacIntyre's critique of the traditional distinction between facts and values prevents us from making any clear-cut parallel distinction in the sense alluded. One may, for example, express his agreement with the central role assigned to the individual and his freedom in the modern world but claim to disagree, however, in the negative evaluation that MacIntyre gives of this fact. However, this 'normative' divergence cannot easily be assumed to be referring to the same reality. For one may disagree to a certain extent with MacIntyre's characterization of the modern individual. One could disagree with MacIntyre's evaluation of modern individualism simply because one has a descriptively different and therefore less dramatic concept of the modern self as MacIntyre has. In that case the evaluation will be knowingly or unknowingly falling on a different phenomenon. Thus, in order to be able to define the divergence as a difference in standards one would have to assume that one is referring to the same object of evaluation and this can only be known by confirming that the descriptions given on both sides are the same. (The fusion of descriptive and normative components must have its limit precisely if one wants to establish the existence of moral disagreement). Of course, the difference in standards can also be expressed not by way of pronouncements of the form " $x+$ (normative) predicate" (where our concept of ' $x$ ' can still involve some evaluative component as in MacIntyre's functional concepts in which case the evaluative moment of the sentence does not need to be expressed 
It is then convenient to interrupt the previous discussion at this point and finally have a look at MacIntyre's argument in order to evaluate it in its actual development. I will simply take for granted both that there is in fact a crisis signalized by moral disagreement and that a historical reflection on the origins of such disagreement is an important condition for its rational settlement and will confine myself to the issue of his historical characterization and evaluation of the nature of contemporary moral disagreement. SinceMacIntyre'scharacter ization of this phenomenon is both conceptually and normatively a negative one, reference is unavoidable both to a correlatively implied positive notion of possible agreement and to a contrasting description of pre-modern moral disagreement ${ }^{17}$.

\section{The Blame of Autonomy}

In the first part of After Virtue (chapters 1-9) MacIntyre is interested in showing that the Enlightenment project of a rational justification of moral principles failed, why it was doomed to fail and what the consequences of this failure are. What the first point of this agenda is concerned, MacIntyre can rely, on the one hand, on a criticism of those philosophers who believed that such justification was possible and advanced a proposal in this respect (Diderot, Hume, Kant). His critique is largely an immanent critique which, as we suggested before, simply applies to them the test of consistency. On the other hand, MacIntyre can take advantage of the conclusions drawn by a growing number of philosophers, from Kierkegaard on,

in an explicitly evaluative predicate) but by way of explicit definitions of the form " $\mathrm{P}^{\prime}$ is (def.) $\mathrm{Y}^{\prime \prime}$ or " ' $\mathrm{x}$ ' is def. $\mathrm{Y}$ " where $\mathrm{P}$ stands for an evaluative predicate, $\mathrm{x}$ stands for a normatively laden 'descriptive' concept (e.g. a functional concept) and $\mathrm{Y}$ for a definition. However, it is clear that MacIntyre does not proceed this way. Such a procedure would run against his historical approach to moral justification.

17 MacIntyre proceeds to describe moral disagreement immediately after the introductory chapter of After Virtue. It is remarkable that MacIntyre refers in its title to "The Nature of Moral Disagreement Today and the Claims of Emotivism"(ibidem: 6, italics added). This suggests that moral disagreement has itself different historical manifestations, this meaning not that the contents of moral disagreement historically diverge, but that the character, i.e. the nature of the disagreement itself is submitted to historical modification. MacIntyre will in fact make a sharp distinction, essential to his argument, between the nature of contemporary (viz. modern) moral disagreement and the nature of moral disagreement (e.g. tragic conflict) in pre-modern societies ( $c f$. ibidem: 224-5). about the non-rational character of basic moral principles and choices (Intuitionism, Emotivism, etc.) since he can present them as driving an adequate conclusion in the face of the factual situation of contemporary moral debate (though illegitimately extrapolating this conclusion as a valid one for moral discourse as such). MacIntyre takes Nietzsche to be the most lucid exponent of this conclusion and, therefore, of the related criticism of the Enlightenment project as a failure ${ }^{18}$. But in order to show that this conclusion, so valid it is if restrictedly applied to modern philosophy, cannot be generalized as valid for moral discourse as such, MacIntyre is committed to the task of showing that such a rational justification is possible. And it is possible since it was already available, MacIntyre claims, in the tradition of Aristotelianism. It was, furthermore, the tradition immediately preceding the rise of the modern world and, hence, the one whose disruption explains in virtue of its disruption why the Enlightenment emerged and had to fail. The failure of the Enlightenment is explained by a lack.

Now, since the first part of After Virtue (chapters 1-9) is both engaged (what finally will turn out to be a single task) in an historically explanation of the failure of the Enlightenment project and in a historical refutation of the generalization implicit in emotivism, a significant part of MacIntyre's constructive criticism is already anticipated before being more cogently and fully developed in the second part (chapters 10-18). The first part of After Virtue already points to what modern moral philosophy so badly lacks. It lacks "some account of the human telos"(ibidem: 52) "a teleological view of human nature" (ibidem: 54). If this basic contention of MacIntyre's argument is right, this absence should explain both the absence of a type of rational moral discourse capable of creating agreement and the emergence of the related claims of emotivism as a moral philosophy. It

\footnotetext{
18 "My own argument obliges me to agree with Nietzsche that the philosophers of the Enlightenment never succeeded in proving grounds for doubting his central thesis [that all rational vindications of morality manifestly fail]." (Ibidem: 117).

19 An obvious exception is utilitarianism. But MacIntyre dismisses the idea of utility as a telos for being just another fiction of modern moral philosophy(cf. ibidem: 64ss.).
} 
should also explain all those salient features of modern culture which represent, according to MacIntyre, the 'social content' and the 'social context' of emotivism ${ }^{20}$ conceived as the last critical stage in the declining process of the modern world. This sociological environment of emotivism includes such features as the gradual obliteration of any "distinction between manipulative and non-manipulative social relationships" (ibidem: 24), the parallel expansion of bureaucratic rationality (the rationality of "matching means to ends"(ibidem: $.25)$, the ascent of effectiveness as a major criterion of practical justification (cf. ibidem: 26), the cultural expansion of the aesthetical attitude (in the Kierkegaardian sense of the word 'aesthetic') which views the world solely as a series of opportunities for enjoyment and whose last enemy is boredom ( $c f$. ibidem: 25).

A crucial thesis of After Virtue is to be found in MacIntyre's attempt to establish an intimate connection between all these ingredients of the social environment of contemporary emotivism ${ }^{21}$ and the hegemony of "the specifically modern self" which, as he puts it, evades "any necessary identification with any particular contingent state of affairs" (ibidem: 31). This lack of (social) identification accounts for its lack of normative criteria. The modern ego is thus given to criticize and relativize everything on account of its ubiquity, of its 'capacity' for arbitrarily adopting any point of view (ibidem:32). ${ }^{22}$ By the same token, it can assume any role because, as MacIntyre paraphrases Sartre, this self "is in and for itself nothing" (ibidem:). Now, this modern self with all the practical pathological consequences of its uprootedness, is no other than the "individual moral agent, freed from hierarchy and teleology" (ibidem: 62), the

20 "But I treated that theory [emotivism G.M.] not only as a philosophical analysis, but also as a sociological hypothesis.(ibidem: 72)."

21 This connection between emotivism, aestheticism and bureaucratic rationality sees MacIntyre perfectly expressed on a theoretical level by the link between Nietzsche and Weber: " [...] I have also noticed that Nietzsche's central thesis was presupposed by Weber's central categories of thought." (ibidem: 114). "So Weber and Nietzsche together provide us with the key theoretical articulations of the contemporary social order; but what they delineate so clearly are the large-scale dominant features of the modern social landscape." (ibidem: 114s.). For the 'small-scale counterparts' of this large-scale picture MacIntyre refers to E.Goffman (ibidem).

22 This attitude has been catalogued by literary criticism as that of Romantic irony. social counterpart of the absolutely autonomous self which Kant presented as the agent of every action which we could legitimately call 'moral'. This is MacIntyre's both conceptually and normatively negative characterization of the modern individual. The history of the emergence of the autonomous modern self - a history which has been described again and again by historians as the history of an unvaluable emancipation and liberation from the bounds of authority and tradition - is, for MacIntyre, not the history of an achievement but the history of a loss (ibidem:60).

Precisely at this point - the issue of freedom as the core of modern moral philosophy - it becomes altogether evident that the history he has to tell is a history informed by standards. Macintyre's criticism of modernity relies first of all in our perceiving the negative character of emotivism in its philosophical and sociological level. Through the causal connection established by MacIntyre between emotivism as the result of the failure to give a rational justification of moral principles and the basic assumptions of modern moral philosophy, Macintyre is inviting us to a critique of the latter. But how can MacIntyre convincingly show the existence of such connection between the modern concept of the self and of freedom (as it has been largely modeled by modern philosophy) and such negative sociological phenomena? Does After Virtue afford a conclusive analysis in this respect?

Again the immense scope that MacIntyre is committed to cover in After Virtue seems to have a proportionally negative effect on those stages of his argument which require a more detailed and conclusive discussion. After Virtue looks in such passages more like the compressed draft of a vast enterprise. Others have spent their whole lives spinning similarly comprehensive arguments. And in fact MacIntyre is relying, in part explicitly, in part implicitly, on such previous labor. This obliged reliance on the conclusions of other large arguments seems to be, by the way, the unavoidable price that contemporary intellectuals have to pay in order to be qualified for the participation on the current 
global evaluation of the Project of the Enlightenment $^{23}$. Macintyre, anyway, is relying on a not fully argued or not quite explicitly shown essential connection between the adequate Weberian cum Nietzschean description of our present socio-cultural reality and all the precedent mainstream of the history of modern philosophy? ${ }^{24}$. But he seems to be aware of his debts. As late as the end of the fifth chapter ("Why the Enlightenment Project had to Fail?") one finds him giving expression to the awareness that the standards that inform his just delineated picture of the pre-modern state of affairs as a state of order are still unargued.

Yet to put matters in this way is to anticipate in an unjustified way. For I am apparently taken it for granted that these changes are indeed to be characterized in terms of such concepts as those of survival, loss of context and consequence loss of clarity; whereas as I noted earlier, many of those who lived through this change in our predecessor culture saw it as a deliverance both from the burdens of traditional theism and the confusions of theological modes of thought. What I have described in terms of a loss of traditional structure and content was seen by the most articulate of the philosophical spokesmen as the achievement by the self of its proper autonomy [...].

Yet whether we view this decisive moment of change as loss or liberation as a transition to autonomy or to anomie, two features of it need to be emphasized. (Ibidem: 60s.).

What MacIntyre subsequently proposes as a way of evaluating the signification of the transition to modernity is an examination both of the "social and political consequences of the change" (ibidem: 61) and of the new conceptual setting, i.e. "the variety of not always coher-

23 One only needs to have a quick glance at the references of the contributions of e.g. F. Lyotard and J. Habermas to this debate.

24 Be it as it may, this strand of his argument makes altogether clear his unacknowledged commitment to a certain tradition of thinkers who have described the contemporary crisis along similar lines: e.g. the Frankfurt School (Habermas excluded) and Heidegger. Couldn't have MacIntyre imbedded more explicitly his practice within this tradition? This could have led him to elevate his position beyond already achieved standpoints within the "historically extended, socially embodied argument" that such tradition as any other tradition represents (ibidem: 222). His failure to do so compels the reader to fall back to objections already stated in the long argument and to give thus nurture to the decried crisis of interminable moral disagreement. ent beliefs and concepts" that the invention of the individual required. Thus, MacIntyre insists in proposing an evaluation of modernity in terms of what he alleges to be some of its actual historical consequences. However, MacIntyre immediately concedes that the history of the political consequences of the transition to autonomy or anomie "is a history yet to be written" (ibidem). Nevertheless, the next chapter, entitled "Consequences of the Failure of the Enlightenment Project", is introduces by the following announcement: "What was then invented was the individual and to the question of what that invention amounted to and its part in creating our own emotivist culture we must now turn" (ibidem). MacIntyre proceeds, in fact, to present those concepts upon which contemporary moral discourse is ultimately based, i.e. the concept of utility and the concept of human rights, as incommensurable moral fictions. By 'incommensurable' MacIntyre alludes once again to the fact that they raise claims that cannot be weighed against each other although they constitute the core of the premises on which contemporary moral arguments are ultimately based (cf. ibidem: 70). Given their incommensurability they give rise to insoluble moral disagreement; given their fictional character despite the apparent objectivity that they support, they provide the ground for emotivism.

Now, as we have said, all these phenomena are to be accounted by the disruption of teleological thought at the beginning of modernity. On the conceptual level the incommensurability, the unaccountability and the fictional character of the basic notions of moral discourse (e.g. 'utility', 'rights') is explained as the result of their complete lack of teleological context and as the result of their being the substitute "for the concepts of an older and more traditional morality" (ibidem: 70). These older concepts were functional concepts which, in virtue of their being imbedded in a teleological context, allowed to overbridge the gap between is and ought (cf. ibidem: 56ss.). The most important of them was the functional concept of man which contained the nowadays missing teleological account of human nature (cf. ibidem: 52). 
Without such an account the virtue ethics that preceded modern morality loses its most essential support. For the virtues are conceived as those dispositions which enable man to reach or near his telos. Now, once modern thought starts to ban the notion of a human telos from practical thought, the sociological counterpart of this development also gets off the ground. Since this telos had been defined for the pre modern man in terms of the task that he was to perform in his society, the modern self "is now thought of as lacking any necessary social identity [...] the self is now thought of as criterionless, because the kind of telos in terms of which it once judged and acted is no longer thought to be credible" (ibidem: 33). The rejection of teleological thought gives birth to the modern individual freed from all social bonds and hierarchies now felt as restrictive (cf. ibidem: 34$)$.

But what motivated the modern critique of teleology? Although MacIntyre insists that the history of political and social change cannot be dissociated from the history of philosophy and that, hence, "the transition into modernity was a transition both in theory and practice and a single transition at that" (ibidem: 61), the fact is that when it comes to explain the historical grounds for the disruption of the teleological conception of man and for the parallel emergence of the modern self, he just focuses on the conceptual side of this development. But even on this level MacIntyre fails to make a clear distinction between what in his account is to be taken as a primal cause of the disruption or already as a certain consequence of it. One has even the impression that MacIntyre is exclusively concerned in pointing out the consequences of the disruption and not at all interested in a detailed explanation of the causes of the disruption itself. And just because he as a theoretician omits any account in this respect we cannot obviously conclude that the process itself was ultimately unmotivated ${ }^{25}$. So what

25 This issue has important consequences for MacIntyre's conception of modern moral philosophy as a mistake. For modern moral philosophy can obviously be interpreted by its defenders as an attempt to correct the shortcomings of pre-modern morality for which MacIntyre could be charged of being symptomatically blind. Couldn't one coun as Macintyre's failure his reluctance to view the origin of modernity as something emerging also from an "historically extended, socially imbedded argument" (ibidem: 222)? are the historical grounds for such catastrophe as presented by MacIntyre, if at all? How far does MacIntyre go beyond the initial metaphor of this catastrophe as a completely unmotivated accident emerging from "a series of environmental disasters" (ibidem: 1)?

In those passages where one can find some information relevant to this question MacIntyre suggests that the abandonment of the teleological framework of pre modern ethical thinking had to do with the appearance of a new conception of reason (cf. ibidem: 53) which was believed to be incapable to grasp ends and to comprehend essences. This new type of reason gave birth to an anti-Aristotelian science ( $c f . i b i-$ dem: 54), i.e. a mechanistic science (whose basic assumptions MacIntyre describes in chapter 7). In the level of morality this new type of reason confined practical thought to the a mere calculus which only decides about the appropriate means to given and unarguable means. MacIntyre is visibly talking about the appearance of what the Frankfurt School, influenced in this respect by Weber, had characterized as the expansion of the limited concept of instrumental reason. But whereas the Frankfurt School traced the origin of instrumental reason all the way back to the very origins of Western culture (see, for instance, the essay on Odysseus in the Dialectic of Enlightenment) and conceived the history of the modern world as the history not of its appearance but of its exclusive hegemony, or whereas Heidegger finds the seeds of modern technique already present in the main concepts of Greek thought, MacIntyre just readily conveys the idea that instrumental reason made its first appearance at the beginning of the modern world. In the picture given by MacIntyre of the pre modern world there seems to be no space at all for types of rationality other than a teleologically informed rationality. But even if MacIntyre would happen to concede the pre modern existence of that type of rationality which he takes to be characteristic of the modern world, even if would qualify his claim as to mean that the specificity of the modern world is not so much given by the sudden coming to be but by the unprecedented hegemony of such type of rationality, he still owes an expla- 
nation for the fact of its sudden overriding role. MacIntyre seems to have no other explanation as that it was a completely unjustified mistake. This impression emerges from the fact that in the long conversation that constitutes, according to his own conception, the course of history he has left no room for the arguments that the modern world once brought and still brings against the ancient and the medieval world. (He believes perhaps that they are sufficiently well known and that they do not deserve being once again seriously weighed). No wonder that at the end of his book he himself is skeptical about the power of his argument in convincing its rivals. MacIntyre's account of modern morals isa' dialectic' of the Enlightenment in which, however, one of the poles of the dialogue has no contribution to make. The other standpoint can be then restored with some minor, if any, qualifications. Aufhebung comes to mean for the one pole complete dissolution and for the other integral conservation.

\section{The Problem: Second-Order Disagreement or Conflict about Conflict}

All this seems to imply that MacIntyre is committed to a presentation of premodern ethics as something that was exempted from any of such problematic phenomema as conceptual incommensurability, rationally insoluble moral disagreement, individualism, emotivism, etc. But the fact is that MacIntyre presents a more complex image of the pre modern world than this might suggest. Striking as this may appear, MacIntyre uses the same or similar formulations to describe the crisis of fifth and fourth century Athens as he used in describing the crisis of the modern world. In relation to this period, MacIntyre refers explicitly to a situation of 'moral disagreement' (ibidem: 133) "incoherence in the use of evaluative language" (ibidem: 131), "incoherence in moral standards and vocabulary" (ibidem: 132), "rival and incompatible demands" (ibidem: 132). MacIntyre is even ready to acknowledge the existence of a Sophoclean self that "transcends the limitations of social roles and is able to put these roles into question" (ibidem: 145). If it were still necessary one could perhaps complete this picture by adding to it an Alcibiades as example of individualism and a Thrasymachus as an example of emotivism. But all this picture needs an essential qualification which makes, according to MacIntyre, all the difference of the world. MacIntyre clearly underlines the fact that fifth century Athens still operated on the conceptual level within the teleological framework that Greek and later medieval ethics never were to abandon. Some pressing questions immediately arise at this point. If all these phenomena already took place to a certain extent in the Greek world and if we are to give of them (and their cause) an equally negative assessment as MacIntyre gave of the analogous phenomena (and their cause) in the contemporary world, then where is their cause to be found? MacIntyre is obviously compelled to exempt the teleological framework in itself from any blame, unless he wants to be blamed himself of an incoherent account. There is however still the possibility that these phenomena, even if they stand in some connection to the teleological framework, turn out to be after all, despite their similar description, essentially different, particularly in their value, either precisely on the account of their being imbedded in such framework (but this would make the presence of teleological thought a value in itself) or in virtue of some other undisclosed factor.

But MacIntyre could reply that he is not at all claiming that teleological ethics as such or as it existed before the Greek Enlightenment avoids the existence of moral disagreement, conceptual incommensurability etc. (This would be by all means problematical on the light of his own exposition). One should perhaps define MacIntyre's claim more precisely by saying that he is arguing that the Aristotelian version of teleological ethics avoids the appearance of such negative phenomena ${ }^{26}$. It is indeed MacIntyre's clear intention to represent Aristotle's ethics as a response, as a certain answer to the situation of moral disagreement and grave

26 If this were Macintyre's thesis one would have to review the history of those societies living under the influence of an Aristotelian type ethics in order to see whether they were exempted from the experience of being incapable to solve moral disagreement in a rational way, etc. 
disorder of the moral language which fifth and fourth century Athens had to face. Aristotle is not to be interpreted as the mere systematical exponent of the putative tradition which might have given rise to such crisis. Aristotle's account of the virtues is interpreted by MacIntyre as a theoretical reaction to this critical situation, i.e. "a response to incoherence" (ibidem: 135). MacIntyre would be thus rather suggesting to take Aristotelianism as such refined version of teleological thought that was already in its inception an elaborate response to problems similar to the one now faced by modern society. Hence, one could conclude, the breakdown of Aristotelianism at the beginning of the modern world was above all the breakdown of a certain way of dealing with the (historically recurrent) critical phenomenon of radical moral disagreement and its related pathology. The birth of modernity lies in the rejection of a certain framework for the treatment of moral dissension.

However the first chapters of the second part of After Virtue, that is, the first part of MacIntyre's constructive effort, are again deceiving. Since he does not explicitly explain the specific reasons for the Athenian crisis nor he makes clear the identity or the difference between its features and those of our present crisis, it cannot be clear how Aristotle's ethics or, for that effect, the virtue ethics that MacIntyre creatively derives from it, can be said to be a solution for this or that crisis. MacIntyre, it seems to me, sets himself to fill the first of these two the gaps of After Virtue in the first chapters of his later Whose Justice? Which Rationality? Macintyre opens this book with the idea that "the history of any society is [...] in key part the history of an extended conflict or set of conflicts. And as it is with societies, so it is with traditions (MacIntyre 1988: 12)." ${ }^{27}$ And some lines further he introduces, as

27 MacIntyre adds immediately: "A tradition is an argument extended through time in which certain fundamental agreements are defined and redefined [...]" (ibidem). Macintyre is thus suggesting that although a tradition is necessarily propelled by certain conflicts that which defines it as a certain tradition is the existence of "certain fundamental agreement." MacIntyre's thesis in After Virtue can be then reformulated in the idea that the real problem in the modern world is not the existence of conflict in general but the existence of a certain kind of basic conflict, namely, the one reflected in fundamental or radical disagreement. For this kind of disagreement goes so far as to undermine the very basis of tradition. MacIntyre's critique of the Enlightenment is a critique of its critique and actual lack of tradition. "Of what did the Enlightenment deprive us? What the Enlightenment made us for in After Virtue, Aristotle as the exponent of a tradition which, as any other tradition (according to Macintyre) is aimed at defining and redefining fundamental agreement:

We inherit from the conflicts of the social and cultural order of the Athenian polis a number of mutually incompatible and antagonistic traditions concerning justice and practical rationality. The two with which I shall be concerned received their classical statements from Thucydides as well as from certain of the sophists and teachers of rhetoric and from Aristotle respectively. (Ibidem: 13).

Macintyre seems to be here acknowledging the existence of fundamental disagreement in fifth and fourth century Athens. If this is the case then Macintyre's specific critique of the modern Enlightenment cannot be said to fall on the existence of radical moral disagreement (as the first pages of After Virtue misleadingly imply) and consequently on those causes which give raise to it in the modern world (at least not in virtue of their being such causes). It must lie then presumably in the way in which such fundamental type of conflict and disagreement (through which a tradition may lose all coherence and dissolve) is handled. In this is what Macintyre is really concerned about then he is actually interested in a second-order disagreement: a disagreement in the way to deal with disagreement. Modernity's dismissal of tradition should be then interpreted as one way of reacting towards radical disagreement, moreover, as one which was born out of the conflict against and the rejection of an alternative (Aristotelian) way of facing radical disagreement.

This seems to me the only way of avoiding the temptation, into which Macintyre himself drives the reader, of accusing Macintyre's argument of certain incoherences. This way out is even more compelling if we take into account what Macintyre finally (in Whose Justice? has to say about the origin of the Athenian fifth and

the most part blind to and what we now need to recover is, so shall I argue, a conception of rational inquiry as embodied in a tradition, a conception according to which the standards of rational justification themselves emerge from and are part of a history [...]." (Ibidem: 7). 
fourth century moral disagreement. In After Virtue Macintyre had characterized the Athenian moral disagreement as the existence of rival conceptions of the virtues (sophrosyne, dike...) and had construed the different conceptions that the Sophists, Plato, the tragedians (especially Sophocles), and Aristotle had of the virtues in general after the disruption of moral disagreement, as different responses to the fact of incoherence ("each informed by a different purpose", cf. Macintyre 1984: 135). But had underlined "at least one thing that they all share." "All do take it for granted that the milieu in which the virtues are to be exercised and in terms of which they are to be defined is the polis (ibidem; 135)." However, there is another common denominator which all Greeks shared (from Homer on) as the other component, besides or along with the polis, of the social context in which every virtue had to be defined or redefined.

We have noticed [...] that the different and rival lists of virtues, different and rival attitudes toward the virtues and different and rival definitions of individual virtues are at home in fifth century Athens and that nonetheless the city-state and the agon provide the shared contexts in which the virtues are to be exercised. (Ibidem: 138).

Now, it seems that these shared contexts can be interpreted as representing a basic agreement which would make it possible to characterize Greek moral thought as a unitary moral tradition despite the internal conflicts arising within it and which could eventually lead to a restoration of its endangered coherence. But Macintyre's more detailed account of the origins of the fifth century Athenian crisis reveals that it is precisely the coexistence of these two different horizons for the definition and redefinition of the virtues which under certain historical circumstances gives rise to the conflict. Polis and agon allow for two different and eventually conflicting sets of values. They embody two different conceptions of the good, or what amounts to the same, of the telos. So it is two different conceptions of goods and ends, already present in the Homeric society but finally colliding in fifth century Athens, what brings the radical moral disagreement that took place in the Greek world. The teleological framework of Greek ethics does not prevent its existence, at least in the way in which the two types of goods are related to each other in the Greek society. Macintyre's thesis requires then a further qualification. It is not any arbitrary version of the teleological framework which allows for the suppression of fundamental disagreement. Such framework certainly allows for a conflicting definition of ends and goods (even a constitutionally conflictive as that one between competitive and cooperative goods). But it is again within such a framework that basic agreement can be restored and traditions can either be revitalized or replaced for new ones. Modernity seems to have drawn the wrong conclusion out of the difficulties of Greek moral history. Modernity has dismissed altogether any teleological framework and has thus deprived itself of the necessary means for healing its wounds. Not that wounds are or should be once and for all avoidable (Macintyre is not pleading for an ideal of absolute harmony), not that new wounds won't be inflicted. But the teleological framework is 9to use a word in vogue, a pharmakon: it is the poison and it is the medicine. In its optimism and in its tendency toward a sharp seclusion of good and evil it has simply moved forward on the assumption that there is (or should be) no ambivalence in the human good. This may point to the reason why the modernity is regularly invited by its critics to put to trial such an assumption by means of a confrontation with tragedy.

\section{Bibliography}

MacIntyre, Alasdair. 1998. Whose Justice? Which Rationality? Notre Dame, Indiana: University of Notre Dame Press.

MacIntyre, Alasdair. 1984 ( $2^{\text {nd }}$ ed.). After Virtue: a Study in Moral Theory. Notre Dame, Indiana: University of Notre Dame Press. 